\title{
AVALIAÇÃO DE INSETICIDAS NO CONTROLE DE PERCEVEJOS E AÇÃO SOBRE INIMIGOS NATURAIS EM VARIEDADES DE SOJA
}

Tiago Roque Benetoli da Silva ${ }^{1}$ Júlio César Sales de Oliveira ${ }^{2}$

Edson Lazarini ${ }^{3}$

Rogério Peres Soratto ${ }^{1}$

\section{RESUMO}

O trabalho foi realizado na Fazenda Experimental de Ensino e Pesquisa, localizada no município de Selvíria - MS, pertencente à FE/ UNESP campus de Ilha Solteira, com o objetivo de avaliar o efeito da utilização de inseticidas no controle dos insetos pragas aliado a três variedades de soja resistentes aos insetos. O delineamento experimental foi o de 4 blocos casualisados em esquema fatorial $3 \times 3$. Foram realizadas as seguintes avaliações: altura das plantas, altura da inserção da primeira vagem, número de vagens por planta, peso de 100 sementes, rendimento, qualidade fisiológica das sementes, número de percevejos, insetos desfolhadores e inimigos naturais. Conclui-se que: a aplicação dos inseticidas não proporcionou acréscimos na produção de sementes, o nível de controle para os percevejos foi obtido apenas no início da segunda quinzena de março; a utilização de variedades de ciclo precoce ou médio pode ser favorável à menor possibilidade de obtenção do nível de dano econômico quanto aos percevejos.

Palavras-chave: Glycine max, pragas, inseticida, produção e qualidade de sementes.

1 Doutorando em Agricultura, Depto de Produção Vegetal, UNESP.FCA, C.P. 237, CEP: 18603-970, Botucatu - SP. e-mail: benetoli@fca.unesp.br; soratto@fca.unesp.br 2 Ex-graduando em Agronomia, FE/UNESP - Ilha Solteira/SP - C.P. 31 - CEP 15.385-000. 3 Depto. de Fitotecnia, Tecnologia de Alimentos e Sócio-Economia - FE/UNESP - Ilha Solteira/SP - C.P. 31 - CEP 15.385-000. 


\section{ABSTRACT}

\section{INSECTICIDES EVALUATION IN THE CONTROL OF THUMBTACKS AND ACTION ON NATURAL ENEMIES IN SOYBEAN VARIETIES}

The work was accomplished in Selvíria Coınty - MS - Brazil, with the objective of evaluating the effect of two insecticides use in the insects plagues control ally to three resistant soybean varieties to insects. A $3 \times 3$ factorial design in 4 randomized blocks was used. Height of the plants, height of the insert of the first bean, number of beans for plant, weight of 100 seeds, yield, physiologic seeds quality, number of thumbtacks, unleaf insects and natural enemies were evaluated. The results showed that: the application of the insecticides did not provide yield increments, the control level for the thumbtacks was just obtained in the beginning of the second fortnight of March and; in the area, the use of precocious or medium varieties cycle can be favorable with relation the smallest possibility of obtaining of the level of economic damage whatever to the thumbtacks.

Key words: Glycine max, plagues, insecticide, yield and quality of seeds.

\section{INTRODUÇÃO}

O cultivo de soja no Brasil tem aumentado nos últimos anos, sendo atualmente um dos principais produtos agrícolas de exportação. Com essa expansão, muitos insetos tiveram suas fontes alimentícias eliminadas, sendo obrigados a se adaptarem a essa nova fonte de alimento, razão pela qual tem sido registrado aumento no número de pragas desta cultura. Entretanto, simultaneamente, ocorrem seus inimigos naturais, que podem atuar na manutenção do equilíbrio de suas populações (Panizzi, 1980).

Os percevejos fitófagos da família pentatomidae foram observados por Villas Bôas (1990), os quais constataram que não ocorreu redução na produção de soja, quando a população foi de quatro percevejos por metro, porém, quando a população aumentou, observaram um menor número de vagens e de sementes por vagem, todavia o peso total de sementes não foi alterado. 
Dentro dessa importante cultura, existem vários tipos de pragas. Panizzi \& Slansky (1985) relacionam trinta e duas espécies de percevejos pentatomídeos na cultura da soja na América do Sul, sendo que Nezara viridula é a espécie mais estudada por atacar diversas culturas e possuir uma ampla distribuição geográfica.

Panizzi (1980) verificou que os percevejos N. viridula, Piezodorus guildinii e Euchistus heros ocorreram em maior população durante as fases de enchimento de vagens e de maturação dos grãos. Galileo \& Heirinchis (1978) observaram a ocorrência de $P$. guildinii nessas mesmas fases do ciclo da cultura.

Dentre os insetos desfolhadores da cultura da soja, segundo Panizzi (1980), A. gemmatalis e Plusia sp. têm se destacado devido ao aumento de sua incidência. Heinrichs \& Silva (1975) registraram picos populacionais de lagartas de $A$. gemmatalis e Plusia sp. na segunda quinzena de janeiro, próximo ao estádio de florescimento da cultura, enquanto que Ramiro et al. (1987) constaram que a incidência de $A$. gemmatalis ocorreu durante todo o ciclo da soja, com maiores picos populacionais na primeira quinzena de janeiro. As populações de $C$. includens foram inferiores às de $A$. gemmatalis e não atingiram níveis populacionais significativos.

Um dos métodos que podem ser associados à resistência de plantas é o uso de inseticidas, visto que existe facilidade de sua manipulação, e o que se observa na prática é que as pessoas que escolhem que inseticida usar não estão conscientes da responsabilidade envolvida (Gazzoni, 1983).

Então o estudo do efeito de inseticidas assume um papel de extrema importância, pois, de acordo com Ferreira et al. (1998), as vendas de inseticidas no Brasil aumentaram de US\$219,7 milhões em 1993 para US $\$ 464,8$ milhões em 1997, um aumento de $112 \%$, destinando-se $20,9 \%$ deste valor somente para a cultura da soja.

Ramiro et al. (1987) utilizando seis variedades de soja, constataram ataques dos percevejos E. heros, $N$. viridula e $P$. guildini em todas as variedades, nas fases de formação das vagens e maturação dos grãos; no entanto, a menor ocorrência foi verificada nas variedades Doko e IAC-9. 
As lagartas de $A$. gemmatalis ocorreram durante toda a fase de desenvolvimento das variedades, mas em menores populações nas variedades IAC-8 e IAC-Foscarin 31. Ramiro et al. (1987), estudando a ocorrência de pragas em seis variedades e duas linhagens de soja, observaram maior incidência de $P$. guildinii na variedade IAC-Foscarin 31. A espécie $E$. heros teve maior ocorrência na variedade IAC-11 e na linhagem IAC-79-1823. As menores populações dessas espécies foram verificadas na linhagem IAC-78-2318. As maiores populações foram constatadas no final da fase vegetativa, variando em função da variedade ou linhagem.

Então é de completa relevância, dentro de um programa de manejo de pragas, conhecer o efeito dos inseticidas sobre os agentes de controle natural de pragas, pois ainda são escassos os estudos a esse respeito (Gazzoni, 1983).

Neste contexto, o presente trabalho teve como objetivo avaliar o efeito da utilização de dois tipos de inseticidas no controle dos insetos pragas (percevejos) e ação sobre inimigos naturais, em três variedades de soja, seus efeitos sobre a produção e qualidade das sementes.

\section{MATERIAL E MÉTODOS}

O presente trabalho foi instalado na Fazenda de Ensino e Pesquisa pertencente à Faculdade de Engenharia de Ilha Solteira - UNESP, localizada no município de Selvíria (MS), com altitude de 335 metros aproximadamente.

O solo do local é do tipo Latossolo Vermelho-Escuro argiloso. A precipitação média anual é de $1.300 \mathrm{~mm}$, a temperatura média anual é de $23,5^{\circ} \mathrm{C}$ e a umidade relativa do ar está entre 70 e $80 \%$ (média anual).

As características químicas do solo foram determinadas antes da instalação do ensaio, seguindo a metodologia proposta por Raij \& Quaggio (1983). Os resultados estão apresentados na Tabela 1.

Os dados meteorológicos foram registrados no posto meteorológico da Fazenda de Ensino e Pesquisa, localizado próximo à área onde se realizou o experimento. 
Tabela 1. Características químicas do solo, avaliadas em $0-20 \mathrm{~cm}$ de profundidade.

\begin{tabular}{cccccccccccc}
$\begin{array}{c}\text { Presina } \\
\left(\mu \mathrm{g} / \mathrm{cm}^{3}\right)\end{array}$ & $\begin{array}{c}\text { M.O. } \\
\left(\mathrm{g} / \mathrm{dm}^{3}\right)\end{array}$ & $\begin{array}{c}\mathrm{pH} \\
\left(\mathrm{CaCl}_{2}\right)\end{array}$ & $\mathrm{K}$ & $\mathrm{Ca}$ & $\mathrm{Mg}$ & $\mathrm{H}+\mathrm{Al}$ & $\mathrm{Al}$ & $\mathrm{SB}$ & $\mathrm{CTC}$ & $\mathrm{V}$ \\
19 & 32,0 & 4,9 & 1,6 & 22,0 & 7,0 & 31,0 & 1,0 & 30,6 & 61,6 & 49 \\
\hline
\end{tabular}

O solo foi preparado pelo sistema convencional, com uma aração e duas gradagens. Antes da última gradagem foi aplicado herbicida com principio ativo trifluralin e a seguir incorporado. A semeadura, realizada mecanicamente, ocorreu em 09/12/1998, com germinação em 15/ 12/1998. Utilizou-se uma densidade de semeadura de 24 sementes por metro de linha, e espaçamento de 0,5m entre linhas. Em 30/12/1998 foi realizado uma aplicação de herbicida em pós-emergência (Flex (fomesafen) $-0,7 \mathrm{~L} / \mathrm{ha}+$ Basagran (bentazon) - 0,8 L/ha) para o controle de plantas daninhas de folha larga. Também foi realizado cultivo mecânico (12/01/1999) com os objetivos de eliminar as plantas daninhas remanescentes, escarificar o solo e propiciar o chegamento de terra no colo das plantas. O florescimento e o início do estádio R5 ocorre em 23/01 e 09/02 (IAC-17), 23/01 e 09/02 (IAC-19) e 02/02 e 24/02 (FT-Cristalina $\mathrm{RCH}$ ), respectivamente.

A adubação realizada foi $200 \mathrm{~kg} / \mathrm{ha}$ da fórmula $04-30-10+\mathrm{B}+$ $\mathrm{Zn}$, segundo a recomendação de Mascarenhas \& Tanaka (1996), mediante os resultados obtidos na análise de solo.

Usaram-se 4 blocos ao acaso com os tratamentos em esquema fatorial de 3 variedades $x 3$ controles dos percevejos. Cada unidade experimental foi constituída por 24 linhas de $25 \mathrm{~m}$ de comprimento. Foram utilizadas as variedades IAC-17, IAC-19 e FT-Cristalina RCH (Tabela 2). Os tratamentos relacionados ao controle de percevejos foram constituídos pela testemunha (sem aplicação), e dois inseticidas (triclorfon e monocrotophos). As aplicações dos inseticidas foram realizadas mecanicamente com um pulverizador de barras (Jacto M-12), equipado com bicos cônicos vazios (D6) e calibrado para uma vazão de $250 \mathrm{~L} / \mathrm{ha}$ de calda. O pulverizador possui uma faixa de aplicação de $12 \mathrm{~m}$, sendo esta a largura da parcela. Descontaram-se as 4 linhas centrais por onde pas- 
sou o trator, restando 10 linhas de cada lado do pulverizador. Dessas, consideraram-se como área útil as 4 linhas centrais com $15 \mathrm{~m}$ de comprimento, em cada lado do pulverizador, onde finalmente foram realizados as avaliações do experimento. Em cada parcela, efetuaram-se duas amostragens para cada avaliação.

Tabela 2. Características das variedades utilizadas no experimento.

\begin{tabular}{lccc}
\hline \multicolumn{1}{c}{ Características } & IAC - $\mathbf{~ 7 ~}$ & IAC - 19 & FT-Cristalina \\
Ciclo médio (dias) & $110-120$ & 135 & RCH \\
Altura da planta (cm) & 70 & $80-100$ & $>140$ \\
Cor da flor & roxa & branca & roxa \\
Hábito de crescimento & determinado & determinado & determinado \\
Cor do tegumento & amarelo & amarelo & amarelo \\
Cor do hilo & preto & marrom & marrom \\
Reação ao Cancro da Haste & resistente & resistente & resistente \\
Peso médio de 100 sementes (g) & 18,0 & 15,0 & 13,0 \\
\hline
\end{tabular}

Como controle fitossanitário, foi realizada uma aplicação de inseticida para o controle de lagartas, no dia 29/01/1999. O produto utilizado foi o Tamaron na dosagem de $0,5 \mathrm{~L} /$ ha do produto comercial. Também foi realizado uma pulverização com fungicida (Benlate 500 g. p.c./ha) em 24/02/1999 nas variedades IAC - 17 e IAC - 19 e em 17/03 na variedade FT-Cristalina $\mathrm{RCH}$, objetivando o controle de doenças fúngicas de final de ciclo.

A aplicação dos inseticidas (controle de percevejos) foi realizada mediante amostragens de percevejo, pelo método do pano branco. As aplicações foram realizadas entre 9:00 e 11:00 horas. As dosagens foram: Azodrin $375 \mathrm{ml} / \mathrm{ha}$ ( 150 g i.a./ha) e Dipterex 1,6 L/ha (800 g i.a./ha). Foram realizadas 3 aplicações sendo elas: 17/03/1999 em todas as variedades, 27/03/99, nas variedades IAC - 19 e FT-Cristalina RCH, e dia 08/ 04/1999 somente na variedade FT-Cristalina $\mathrm{RCH}$.

Esse diferente número de aplicações em cada variedade foi devido aos diferentes ciclos que possuem. Assim que a variedade manifesta aparência de proximidade final de ciclo, tendo como início o 
amarelecimento das folhas, não era realizado mais controle, devido ao período de carência dos inseticidas.

A colheita foi realizada nos dias 30/03 (105 dias), 07/04 (113 dias) e 15/04/1999 (121 dias), nas variedades IAC-17, IAC-19 e FT-Cristalina $\mathrm{RCH}$ respectivamente.

No presente experimento foram realizadas as seguintes avaliações:

Altura das plantas e altura de inserção das primeiras vagens: coletaram-se 5 plantas seguidas na linha em cada repetição, no mesmo local onde se avaliou a produção. Essas plantas, após a identificação, foram levadas para o laboratório onde determinou-se a altura das plantas e de inserção das primeiras vagens, medindo-se, respectivamente, a distância entre o colo das plantas e o ápice da haste principal e o colo e a inserção das primeiras vagens.

Número de vagens / planta: as mesmas plantas coletadas para avaliar a altura de planta e de inserção das primeiras vagens, foram utilizadas para avaliação do número de vagens por planta, sendo o valor obtido uma média.

Produção: para a avaliação da produção de sementes, foram arrancadas 4 linhas de 3 metros de comprimento, para cada repetição avaliada. Essas plantas foram levadas para o terreiro e trilhadas mecanicamente. A produção final foi estipulada em $\mathrm{kg} / \mathrm{ha}$, com $13 \%$ de umidade (base úmida).

Peso de 100 sementes: simultaneamente a pesagem da produção obtida, foi realizada a pesagem de duas amostras de 100 sementes. Estas pesagens também foram corrigidas para 13\% de umidade (base úmida).

Avaliação do número de insetos desfolhadores, percevejos e inimigos naturais: as amostragens dos artrópodos fitófagos e de predadores entomófagos foram realizadas semanalmente, utilizando-se o método do pano. Essas amostragens iniciaram no período entre o florescimento e formação de vagens estendendo-se até o ponto de colheita. Foram realizadas amostragem por tratamento, em cada avaliação. As avaliações foram feitas nas seguintes datas: 4/2, 13/2, 20/2, 27/2, 6/3, 13/3, 20/3, 27/3, 3/4 e 10/4.

Também foi realizado uma amostragem em 17/3, imediatamente antes da primeira aplicação dos inseticidas. 


\section{RESULTADOS E DISCUSSÃO}

O resumo da análise estatística e os resultados obtidos referentes às características agronômicas estão apresentados na Tabela 3 , onde se observa que não houve efeito significativo dos inseticidas e da interação inseticidas $X$ variedades nas características avaliadas. Quanto a característica altura de inserção das primeiras vagens, verifico'1-se que as variedades IAC-17 e IAC-19 proporcionaram valores superiores ao da variedade FTCristalina RCH. No entanto, nos valores observados para número de vagens por planta, o comportamento das variedades foi oposto, ou seja, a variedade FT-Cristalina $\mathrm{RCH}$ produziu mais vagens que as variedades IAC17 e IAC-19. Na característica altura de plantas, o maior valor também foi encontrado para a variedade FT-Cristalina $\mathrm{RCH}$, tendo comportamento intermediário a variedade IAC- 19 e a variedade IAC- 17 com menor valor.

Na coluna, médias seguidas pela mesma letra não diferem entre si pelo Teste de Tukey ao nível de $5 \%$ de probabilidade.

Os valores observados para altura de plantas encontram-se de acordo com os dados da Tabela 2, referentes às características das variedades utilizadas. Isso demonstra que essas variedades estão adaptadas as condições climáticas da região, podendo ser perfeitamente recomendadas quanto a esse parâmetro.

Quanto ao menor ciclo observado (105, 113 e 121 dias respectivamente para as variedades IAC-17, IAC-19 e FT-Cristalina RCH) em relação aos dados da Tabela 2, pode ser devido ao atraso na época de semeadura. No entanto, verificou-se que a redução do ciclo não afetou o desenvolvimento vegetativo das variedades, que apresentaram tamanhos compativeis com seu potencial genético (Tabela 2).

De acordo com Queirós (1981), a altura de inserção das primeiras vagens desejável para a colheita mecânica da soja, deve ser superior a 13 $\mathrm{cm}$. Sendo assim, pelos dados obtidos, observa-se que apenas a variedade FT-Cristalina RCH proporcionou valores abaixo do desejável.

O melhor desenvolvimento das plantas da variedade FT-Cristalina $\mathrm{RCH}$, fez com que ela também produzisse um maior número de vagens por planta, apesar de não haver diferença significativa entre as vari- 
Tabela 3. Análise de variância e valores médios encontrados para altura de inserção das primeiras vagens e de planta $(\mathrm{cm})$, número de vagens por planta, produção de sementes $(\mathrm{kg} / \mathrm{ha})$ e peso de 100 sementes (g), em três variedades de soja, sem e com inseticida.

\begin{tabular}{|c|c|c|c|c|c|}
\hline $\begin{array}{l}\text { Variedades/ } \\
\text { Inseticidas }\end{array}$ & $\begin{array}{l}\text { Altura da } \\
\text { inserção }\end{array}$ & $\begin{array}{l}\text { Altura das } \\
\text { plantas }\end{array}$ & $\begin{array}{c}\text { Número de } \\
\text { vagens por } \\
\text { planta }\end{array}$ & Produção & $\begin{array}{c}\text { Peso de } \\
100 \\
\text { sementes }\end{array}$ \\
\hline IAC -17 & $21,7 \mathrm{a}$ & $75 \mathrm{c}$ & $46,8 \mathrm{~b}$ & $3366 \mathrm{a}$ & $14,2 \mathrm{a}$ \\
\hline IAC - 19 & $17,8 \mathrm{a}$ & $94 \mathrm{~b}$ & $51,4 \mathrm{~b}$ & $3503 \mathrm{a}$ & $14,5 \mathrm{a}$ \\
\hline FT - Cristalina & $8,8 \mathrm{~b}$ & $119 \mathrm{a}$ & $77,7 \mathrm{a}$ & $2463 b$ & $12,7 \mathrm{~b}$ \\
\hline Testemunha & 16,6 & 98 & 56,3 & 3106 & 13,6 \\
\hline Triclorfon & 16,1 & 96 & 61,2 & 3011 & 13,8 \\
\hline Monocrotophós & 15,7 & 95 & 58,4 & 3212 & 14,1 \\
\hline Teste F & & & & & \\
\hline Variedade (V) & $34,25 * *$ & $220,34 * *$ & $19,93 * *$ & $57,89 * *$ & $20,11 * *$ \\
\hline Inseticida (I) & $0,16 \mathrm{NS}$ & $0,81 \mathrm{NS}$ & $0,44 \mathrm{NS}$ & $1,87 \mathrm{NS}$ & $1,37 \mathrm{NS}$ \\
\hline Interação V X I & $0,20 \mathrm{NS}$ & $1,62 \mathrm{NS}$ & $1,63 \mathrm{NS}$ & $0,61 \mathrm{NS}$ & $0,25 \mathrm{NS}$ \\
\hline DMS Tukey 5\% & & & & & \\
\hline Variedades & 4,0 & 5,3 & 13,2 & 262 & 0,7 \\
\hline Inseticidas & - & - & - & - & - \\
\hline $\mathrm{CV}$ & $24,37 \%$ & $5,41 \%$ & $22,07 \%$ & $8,26 \%$ & $4,91 \%$ \\
\hline
\end{tabular}

Na coluna, médias seguidas pela mesma letra não diferem entre si pelo teste de Tukey ao nivel de $5 \%$ de probabilidade

edades IAC-19 e IAC-17 quanto a esse parâmetro. Também verificou-se que o menor desenvolvimento da variedade IAC-17 proporcionou um menor número de vagens por planta.

Quanto a produção de sementes, verifica-se na Tabela 3 que as variedades IAC-17 e IAC-19 proporcionaram valores superiores significativamente em relação a variedade FT-Cristalina $\mathrm{RCH}$. Essa mesma tendência também foi observado para o peso de 100 sementes. O maior número de vagens por planta apresentado pela variedade FT-Cristalina $\mathrm{RCH}$ não proporcionou beneficio quanto a produção, podendo o peso de 100 sementes ter tido forte influência neste parâmetro. Segundo Miranda et al. (1982), quando ocorrem condições ideais de temperatura do ar e de umidade do solo no período de enchimento das sementes das variedades tardias, elas apresentam maior produtividade que as precoces, pois têm maior potencial de produção. 
De acordo com os dados meteorológicos (precipitação, temperaturas máximas e mínimas) quando comparados com os da época de ocorrência do periodo após início do estádio R5 (09/02, 09/02 e 24/02, respectivamente, para as variedades IAC-17, IAC-19 e FT-Cristalina RCH), verifica-se que, para a variedade FT-Cristalina $\mathrm{RCH}$, a qual possui ciclo mais longo, foi caracterizada pela ocorrência de condições climáticas adversas, principalmente na fase final de enchimento das sernentes, podendo este ser o principal motivo da menor produtividade e encurtamento do seu ciclo. As variedades IAC-19 e IAC-17, por se encontrarem em fase mais avançada do desenvolvimento da semente, os efeitos da estiagem e altas temperaturas não apresentam diferença entre si quanto a produtividade, mas propiciaram produções muito superiores à de FT-Cristalina RCH.

Quanto ao número de percevejos $/ \mathrm{m}$, verificou-se que os inseticidas proporcionaram seu controle, mas somente o monocrotophós se diferenciou da testemunha. Através das amostragens, em média de variedades e inseticidas, verificou-se que o número de percevejos foi crescente até as aplicações dos inseticidas (17/3) vindo a cair na amostragem seguinte e novamente retornou seu crescimento após 10 dias da aplicação dos inseticidas (Tabela 4).

$\mathrm{Na}$ Tabela 5 pode-se verificar que, até o momento da aplicação, não ocorreu diferença entre variedades e a testemunha e aquelas que receberam os tratamentos com inseticidas. Entre as variedades, somente observou-se diferença significativa no dia da $1^{\mathrm{a}}$ e $2^{\mathrm{a}}$ aplicações, apresentando a variedade FT-Cristalina RCH sempre o maior número de percevejos. Na amostragem de $27 / 3$, isso pode ter ocorrido em função de as variedades IAC-17 e IAC-19 já se encontrarem em fase adiantada de ciclo, com início de senescência, enquanto a variedade FT-Cristalina RCH estava em fase de enchimento das sementes. Quanto ao efeito dos inseticidas, verificou-se que após a aplicação, não houve diferença significativa entre eles quanto ao controle; no entanto, 10 dias pós a aplicação, o produto à base de triclorfon proporcionou controle, que diferiu significativamente da testemunha.

Portanto, pelo fato de não se ter obtido diferença significativa entre variedades, para a característica número de percevejos/metro (Tabela 4). No entanto, obteve-se diferença significativa quanto a produção 
Tabela 4. Análise de variância e média do número de percevejos, insetos desfolhadores e inimigos naturais, obtidos nas diferentes amostragens, em função das variedades de soja e inseticidas utilizados.

\begin{tabular}{|c|c|c|c|c|c|c|}
\hline \multirow{3}{*}{$\begin{array}{c}\text { Amostragens/ } \\
\text { Variedades/ } \\
\text { Inseticidas }\end{array}$} & \multicolumn{6}{|c|}{ Artrópodos $/ 4$ metros de fileira } \\
\hline & \multicolumn{2}{|c|}{ Percevejos $^{2}$} & \multicolumn{2}{|c|}{ Desfolhadores ${ }^{3}$} & \multicolumn{2}{|c|}{ Inimigos Naturais ${ }^{4}$} \\
\hline & Transf. $^{1}$ & Originais & Transf. & Originais & Transf. & Originais \\
\hline $04 / 2$ & $0,83 \mathrm{~d}$ & 0,18 & $1,11 \mathrm{e}$ & 0,73 & $0,95 \mathrm{~d}$ & 0,40 \\
\hline $13 / 2$ & $0,90 \mathrm{~d}$ & 0,31 & $1,63 \mathrm{~d}$ & 2,17 & $1,18 \mathrm{~cd}$ & 0,89 \\
\hline $20 / 2$ & $0,87 \mathrm{~d}$ & 0,25 & $2,36 \mathrm{ab}$ & 5,10 & $1,45 \mathrm{abc}$ & 1,61 \\
\hline $27 / 2$ & $1,06 \mathrm{~cd}$ & 0,61 & $2,68 \mathrm{a}$ & 6,70 & 1,68 a & 2,32 \\
\hline $06 / 3$ & $1,32 \mathrm{bc}$ & 1,24 & $2,02 \mathrm{bc}$ & 3,59 & $1,51 \mathrm{ab}$ & 1,79 \\
\hline $13 / 3$ & $2,10 \mathrm{a}$ & 3,93 & $1,83 \mathrm{~cd}$ & 2,84 & $1,77 \mathrm{a}$ & 2,62 \\
\hline $17 / 3$ & $2,31 \mathrm{a}$ & 4,84 & $1,99 \mathrm{~cd}$ & 3,46 & $1,68 \mathrm{a}$ & 2,31 \\
\hline $20 / 3$ & $1,66 \mathrm{~b}$ & 2,25 & $1,21 \mathrm{e}$ & 0,96 & $1,29 \mathrm{bc}$ & 1,17 \\
\hline $27 / 3$ & $2,14 \mathrm{a}$ & 4,08 & $1,72 \mathrm{~cd}$ & 2,46 & $1,14 \mathrm{~cd}$ & 0,80 \\
\hline IAC-17 & 1,4 & 1,47 & $1,61 b$ & 2,10 & 1,39 & 1,43 \\
\hline LAC-19 & 1,51 & 1,78 & $1,60 \mathrm{~b}$ & 2,07 & 1,34 & 1,31 \\
\hline FT-Cristalina & 1,48 & 1,68 & $2,30 \mathrm{a}$ & 4,8 & 1,48 & 1,71 \\
\hline Testemunha & $1,56 \mathrm{a}$ & 1,95 & 1,81 & 2,77 & 1,42 & 1,5 \\
\hline Triclorfon & $1,43 \mathrm{ab}$ & 1,54 & 1,87 & 3,00 & 1,41 & 1,5 \\
\hline Monocrotofós & $1,40 \mathrm{~b}$ & 1,46 & 1,84 & 2,88 & 1,39 & 1,44 \\
\hline \multicolumn{7}{|l|}{ Teste $\mathbf{F}$} \\
\hline Amostragem (A) & \multicolumn{2}{|c|}{$52,11 * *$} & \multicolumn{2}{|c|}{$35,70 * *$} & \multicolumn{2}{|c|}{$13,11 * *$} \\
\hline Variedade (V) & \multicolumn{2}{|c|}{ 1,38 n.s. } & \multicolumn{2}{|c|}{$67,44 * *$} & \multicolumn{2}{|c|}{2,68 n.s. } \\
\hline Inseticida (I) & \multicolumn{2}{|c|}{$3,40 *$} & \multicolumn{2}{|c|}{0,40 n.s. } & \multicolumn{2}{|c|}{0,08 n.s. } \\
\hline$A \times V$ & \multicolumn{2}{|c|}{$2,72 * *$} & \multicolumn{2}{|c|}{$10,45 * *$} & \multicolumn{2}{|c|}{$2,86 * *$} \\
\hline$A \times I$ & \multicolumn{2}{|c|}{$1,92 *$} & \multicolumn{2}{|c|}{$2,55 * *$} & \multicolumn{2}{|c|}{0,8 n.s. } \\
\hline V x I & \multicolumn{2}{|c|}{0,83 n.s. } & \multicolumn{2}{|c|}{0,68 n.s. } & \multicolumn{2}{|c|}{$4,97 * * *$} \\
\hline$A \times V \times I$ & \multicolumn{2}{|c|}{0,92 n.s. } & \multicolumn{2}{|c|}{0,65 n.s. } & \multicolumn{2}{|c|}{ 1,12 n.s. } \\
\hline \multicolumn{7}{|l|}{ DMS Tukey 5\% } \\
\hline Amostragens & \multicolumn{2}{|c|}{0,36} & \multicolumn{2}{|c|}{0,37} & 0 & \\
\hline Variedades & 0 , & & & & 0 , & \\
\hline Inseticidas & & & & & 0 & \\
\hline $\mathrm{CV}$ & 34, & $1 \%$ & 27 , & $2 \%$ & 33,1 & $6 \%$ \\
\hline
\end{tabular}

1 A análise refere-se aos dados transformados em $(x+0,5)^{1 / 2}$

2 Piezodorus guildinii, Euchistus heros, Edessa meditabunda

3 Diabrotica speciosa, Colaspis sp., Megacelis sp.

4 Geocoris sp., aranhas

Médias seguidas de mesma letra dentro do parâmetro não diferem estatisticamente entre si pelo teste de Tukey a 5\% de probabilidade. 


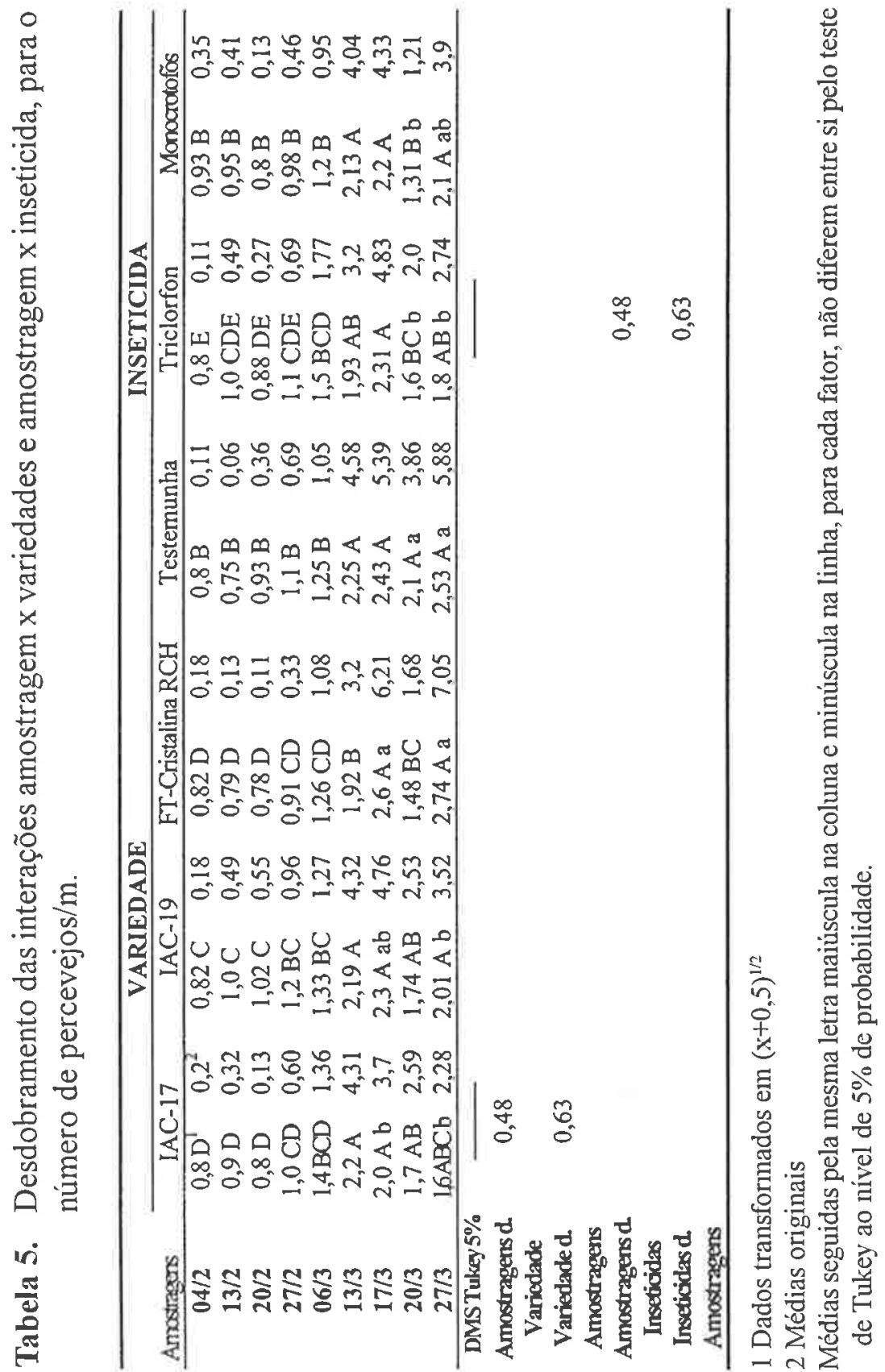


destas variedades (Tabela 3), sendo neste caso a variedade FT-Cristalina $\mathrm{RCH}$ a que produziu menos; pode-se atribuir esta menor produtividade, principalmente aos efeitos climáticos adversos que atuaram por maior intervalo de tempo nesta variedade, devido a seu ciclo. Fatores como, as diferenças significativas obtidas para o número de percevejos/metro (Tabela 5), nas amostragens de $17 / 3$ e $27 / 3$, sendo sempre maior o número proporcionado pela variedade FT-Cristalina $\mathrm{RCH}$ e o maior número de insetos desfolhadores também observado nesta variedade (Tabela 4), podem ser considerados como fatores adicionais às condições climáticas, que levaram a menor produtividade dessa variedade.

Observa-se, pelos dados da Tabela 5, que, nas condições em que o experimento foi desenvolvido, a infestação acima de 4 percevejos $/ \mathrm{m}$, somente foi obtida praticamente a partir da amostragem de 13.3. Segundo Villas Boas (1990), é a partir desse valor (4 percevejos $/ \mathrm{m}$ ) que há influência na produção. Portanto, verifica-se que, por exemplo, para variedades precoces, semeadas no mês de novembro, o período da primeira quinzena de março já é considerado como o período final de maturação, onde $o$ ataque de percevejos poderia influenciar muito pouco, sendo variedades com esta característica de ciclo, uma boa opção para a região. No entanto, no caso da utilização de variedades tardias, ainda existiria um maior período para ação dos percevejos, podendo esta lavoura ainda receber insetos de outras lavouras com variedades de ciclo precoce ou médio que já iniciaram a senecência ou foram colhidas, proporcionando um maior dano da praga à cultura.

Quanto aos insetos desfolhadores, verificou-se através da Tabela 4 que os maiores números destes foram verificados durante o mês de fevereiro, provavelmente devido a cultura se encontrar no estádio de maior desenvolvimento vegetativo, bem enfolhada e sem sinal de senecência. $O$ baixo número encontrado na primeira quinzena de fevereiro, pode ser provavelmente devido ao químico realizado em $26 / 1$ e as condições de umidade e temperatura que favoreceram o controle microbiano (fungos) das lagartas. Quanto ao efeito dos inseticidas, verificou-se (Tabela 6) que após a aplicação dos mesmos, realizada em 17/3, houve uma redução no número destes insetos, inclusive na parcela testemunha, que não recebeu inseticida. 


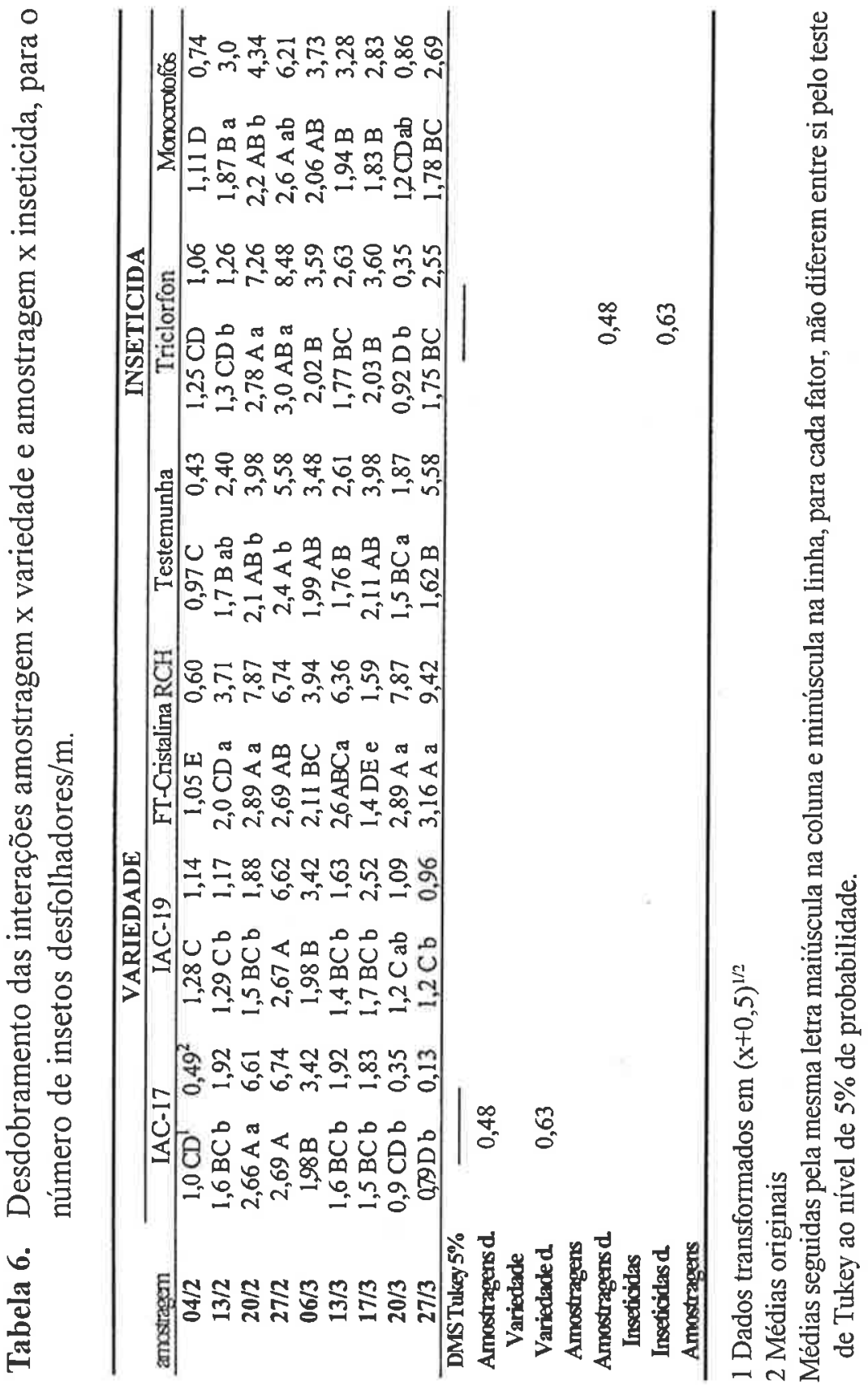




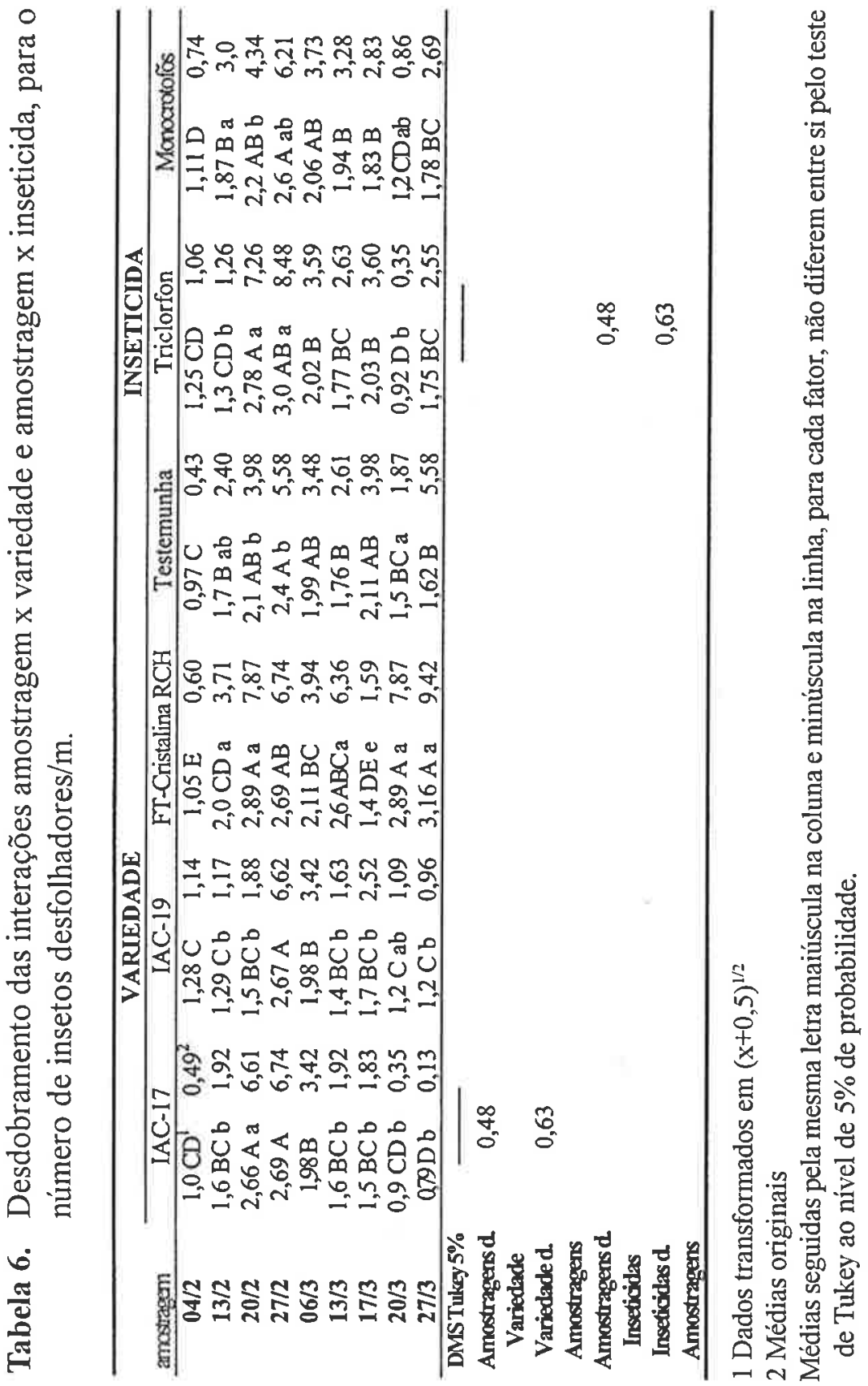


Quanto ao número de inimigos naturais obtido (Tabela 4), verificou-se que houve diferença significativa entre amostragens. Também as interações amostragens $x$ variedades e variedades $x$ inseticidas, foram significativas quanto a este parâmetro. Através dos dados da Tabela 4, verifica-se que os maiores valores foram obtidos durante a segunda quinzena de fevereiro e a primeira quinzena de março.

Na Tabela 7 verifica-se que após a primeira aplicação dos inseticidas para o controle dos percevejos, houve também uma forte redução no número dos inimigos naturais, inclusive no tratamento testemunha. $\mathrm{Na}$ variedade $\mathrm{FT}$-Cristalina $\mathrm{RCH}$, em função de seu maior ciclo, a população de inimigos naturais continuou baixa até o final do ciclo. Deve-se considerar que, nesta variedade, ainda houve mais duas aplicações de inseticidas para o controle dos percevejos (27/3 e 8/4). No entanto, a população de inimigos naturais continuou baixa também no tratamento testemunha, podendo ter sido influenciada pelas aplicações dos inseticidas próximo a estas parcelas ou pelas condições ambientais, diminuição da precipitação principalmente, que ocorreu na segunda quinzena de março e primeira quinzena de abril. Nas variedades IAC-17 e IAC-19, após a primeira aplicação dos inseticidas, as variedades entraram em estádio final de maturação, com o início de senescência das plantas, o que pode ter auxiliado na diminuição dos inimigos naturais, também no tratamento testemunha.

Na Tabela 8, observa-se que o número de inimigos naturais foi menor significativamente nas parcelas que receberam a aplicação do inseticida monocrotofós, e que também, nestas parcelas, o número de inimigos naturais foi menor, para a variedade IAC-17, em relação às demais variedades.

Segundo Gazzoni (1983), é importante conhecer o efeito dos inseticidas sobre os agentes de controle natural de pragas. No entanto, no presente trabalho não se pode verificar esta influência, devido ao tratamento testemunha também apresentar redução do número de inimigos naturais, após a aplicação dos inseticidas nos demais tratamentos.

Através dos dados obtidos, pode-se observar que o maior número de inimigos naturais foi obtido quando se tinha um maior número de insetos desfolhadores. A época de ocorrência dos inimigos naturais no experimento também foi semelhante ao período observado por Morais et al. (1991). 
Tabela 7. Desdobramento das interações amostragem $x$ variedades significativa, para o número de inimigos naturais $/ \mathrm{m}$.

\begin{tabular}{|c|c|c|c|c|c|c|}
\hline \multirow{3}{*}{$\begin{array}{c}\text { Amostragem } \\
04 / 2\end{array}$} & \multicolumn{6}{|c|}{ Variedades } \\
\hline & \multicolumn{2}{|c|}{ IAC -17} & \multicolumn{2}{|c|}{ IAC-19 } & \multicolumn{2}{|c|}{ FT-Cristalina RCH } \\
\hline & $0,83 \mathrm{C}^{\mathrm{J}}$ & $0,20^{2}$ & $1,18 \mathrm{AB}$ & 0,89 & $0,84 \mathrm{E}$ & 0,2 \\
\hline $13 / 2$ & $1,41 \mathrm{ABC}$ & 1,50 & $1,07 \mathrm{AB}$ & 0,65 & $1,06 \mathrm{DE}$ & 0,61 \\
\hline $20 / 2$ & $1,64 \mathrm{AB}$ a & 2,18 & $1,19 \mathrm{AB} b$ & 0,91 & $15 \mathrm{BCD}$ ab & 1,86 \\
\hline $27 / 2$ & $1,90 \mathrm{~A}$ & 3,11 & $1,5 \mathrm{AB}$ & 1,75 & $1,64 \mathrm{ABC}$ & 2,20 \\
\hline $06 / 3$ & $1,31 \mathrm{ABC}$ & 1,24 & $1,64 \mathrm{~A}$ & 2,18 & $1,6 \mathrm{ABCD}$ & 2,02 \\
\hline $13 / 3$ & $1,6 \mathrm{AB} \mathrm{b}$ & 1,96 & $1,57 \mathrm{~A} \mathrm{~b}$ & 1,95 & 2,17 A a & 4,20 \\
\hline $17 / 3$ & $1,6 \mathrm{AB}$ & 2,08 & $1,50 \mathrm{AB}$ & 1,73 & $1,93 \mathrm{AB}$ & 3,21 \\
\hline $20 / 3$ & $1,06 \mathrm{BC} \mathrm{b}$ & 0,61 & $1,51 \mathrm{AB}$ a & 1,79 & 1,3 CDEab & 1,22 \\
\hline $27 / 3$ & $1,15 \mathrm{BC}$ & 0,83 & $0,95 \mathrm{~B}$ & 0,41 & $1,32 \mathrm{CDE}$ & 1,25 \\
\hline DMSTukcy 5\% & \\
\hline $\begin{array}{l}\text { Amostragans } \\
\text { d Variedades }\end{array}$ & \multicolumn{6}{|c|}{0,44} \\
\hline $\begin{array}{l}\text { Variedades d. } \\
\text { Amostragens }\end{array}$ & \multicolumn{6}{|c|}{0,59} \\
\hline
\end{tabular}

1 Dados transformados em $(x+0,5)^{1 / 2}$

2 Médias originais

Médias seguidas pela mesma letra maiúscula na coluna e minúscula na linha, para cada fator, não diferem entre si pelo teste de Tukey ao nível de $5 \%$ de probabilidade.

Portanto, verifica-se que trabalhos com este objetivo devem ser realizados por mais de um ano e que, de preferência, sejam anos consecutivos, para se avaliar o efeito das condições ambientais na população das pragas avaliadas e dos inimigos naturais. Apesar dos cuidados tomados na aplicação dos inseticidas e pela tamanho da bordadura utilizada entre parcelas, deve-se atentar para estes fatos nesse tipo de trabalho, devendo manter o maior isolamento possível da testemunha para que a deriva da aplicação dos inseticidas, odor dos mesmos ou outro fator, não interfira na população de insetos/inimigos naturais da parcela testemunha.

\section{CONCLUSÕES}

A aplicação dos inseticidas não proporcionou acréscimos na produção de sementes.

O nível de controle para os percevejos foi obtido apenas no início da segunda quinzena de março e, na região, a utilização de varieda- 
Tabela 8. Desdobramento das interações variedades $x$ inseticida significativa, para o número de inimigos naturais $/ \mathrm{m}$.

\begin{tabular}{|c|c|c|c|c|c|c|}
\hline \multirow{3}{*}{$\begin{array}{c}\text { Variedades } \\
\text { IAC-17 }\end{array}$} & \multicolumn{6}{|c|}{ Inseticidas } \\
\hline & \multicolumn{2}{|c|}{ Testemunha } & \multicolumn{2}{|c|}{ Triclorfon } & \multicolumn{2}{|c|}{ Monocrotofös } \\
\hline & $1,53 \mathrm{a}^{1}$ & $1,86^{2}$ & $1,48 \mathrm{a}$ & 1,70 & $1,14 \mathrm{~B} \mathrm{~b}$ & 0,81 \\
\hline IAC-19 & 1,30 & 1,19 & 1,29 & 1,16 & $1,44 \mathrm{~A}$ & 1,59 \\
\hline Cristalina & 1,41 & 1,49 & 1,47 & 1,65 & $1,58 \mathrm{~A}$ & 2,01 \\
\hline DMSTulzy5\% & & & & & & \\
\hline $\begin{array}{l}\text { Variedades d } \\
\text { Inseticidas }\end{array}$ & & & & & & \\
\hline Inseticidas d & & & & & & \\
\hline Variedades & & & & & & \\
\hline
\end{tabular}

1 Dados transformados em $(x+0,5)^{1 / 2}$

2 Médias originais

Médias seguidas pela mesma letra maiúscula na coluna e minúscula na linha, para cada fator, não diferem entre si pelo teste de Tukey ao nivel de 5\% de probabilidade.

des de ciclo precoce ou médio pode ser favorável com relação a menor possibilidade de obtenção do nivel de dano econômico quanto aos percevejos.

\section{REFERÊNCIAS BIBLIOGRÁFICAS}

BRASIL. Ministério da Agricultura. Regras para Análises de Sementes. Brasília: SIVAD/DNVD/CLAV, 1992. 365p.

FERREIRA, C.R.R.P.T.; BARBOSA, M.Z.; TSUECHIRO, A. Evolução e Sazonalidade das Vendas de Inseticidas no Brasil, 1993-97. In: REUNIÃO ANUAL DO INSTITUTO BIOLÓGICO, 11., São Paulo, 1998. Arquivos do Instituto Biológico. São Paulo: Instituto Biológico, 1998. p. 38 .

GALILEO, M.H.M.; HEINRICHS, E.A. Efeito dos Danos Causados por Piezodorus guildinii (Westwood, 1937) (Hemiptera: Pentatomidae) em Diferentes Niveis e Épocas de Infestação, no Rendimento de Grãos de Soja (Glycine max (L.) Merrill). Anais da Sociedade Entomológica do Brasil, 7(1):20-25, 1978.

GAZZONI, D.L. Manejo de Pragas de Soja. In: VERNETTI, F.J. Soja: 
Planta, Clima, Pragas, Moléstias e Invasoras. Campinas: Cargill, 1983. p.191-281.

HEINRICHS, E.A.; SILVA, R.F.P. Estudo de Niveis de População de Anticarsia gemmatalis (Hubner, 1818) e Plusia sp. em Soja no Rio Grande do Sul. Agronomia Sulriograndense. 11(1):29-35, 1975. MASCARENHAS, H.A.A.; TANAKA, R.T. Soja. In: RAIJ, B. van.

Recomendação de Adubação e Calagem para o Estado de São

Paulo. Campinas: IAC, 1996. p.202-203 (Boletim Técnico 100) MIRANDA, M.A.C.; MYASAKA, S.; MASCARENHAS, H.A.A. Melhoramento da Soja no Estado de São Paulo. In: A Soja no Brasil Central. Campinas: Fundação Cargill, 1982. p.284-301. MORAIS, R.R.; LOECKK, A.; BERLAMINO, L.C. Flutuação Populacional de Plusinae e Anticarsia gemmatalis Huebner, 1818 (Lepdoptera: Noctuidae) em Soja no Rio Grande do Sul. Pesquisa Agropecuária Brasileira. 26(1):51-55, 1991.

PANIZZI, A.R. Manejo de Pragas da Soja, Situação Atual e Perspectivas Futuras. In: CONGRESSO BRASILEIRO DE ENTOMOLOGIA, 6., Campinas, 1980. Anais. Campinas: Fundação Cargill, 1980. p.3030-3022. PANIZZI, A.R.; SLANSKY, F. Review of Phtophagus pentatomids Associated with Soybean in the Americas. Florida Entomology, 68(1):184-214, 1985.

QUEIRÓS, F.F. Recomendações Técnicas para Colheita Mecânica. In: MYASAKA, S.; MEDINA, I.C. (ed.) A Soja no Brasil. Campinas: ITAL, 1981. p.701-710.

RAIJ, B. van., QUAGGIO, J.A. Métodos de Análise de Solo para Fins de Fertilidade. Campinas: Instituto Agronômico, 1983. 31 p. (Boletim Técnico, 81).

RAMIRO, Z.A.; BATISTA FILHO, A.; MACHADO, L.A. Levantamento de Pragas e Inimigos Naturais em Seis Cultivares de Soja. O Biológico, 53(13):7-23, 1987.

VILLAS BÔAS, C. Efeito de Diferentes Populações de Percevejos Sobre o Rendimento e Seus Componentes, Características Agronômicas e Qualidade de Sementes de Soja. Empresa Brasileira de Pesquisa Agropecuária. 2(1):43, 1990. 